\title{
An Incipient Framework on the Factors that Make up Elementary Principals Data Literacy
}

\author{
Robert Przybylski, Ph.D. \\ Assistant Professor \& Foreign Expert \\ Department of Educational Administration and Policy \\ College of Education Science \\ Nanjing Normal University \\ China
}

\begin{abstract}
For the past several decades, federal and state/provincial governments in the United States and Canada have devoted a great deal of time and effort to constructing initiatives and accountability measures in the hopes of improving student achievement. This has profoundly affected the roles that elementary school principals now must perform in the areas of leadership and decision making. In efforts to attain benchmarks, a certain level of literacy about data can be of significant benefit. However, the body of empirical literature on principal data literacy is limited and an understanding of the full potential of having principals' data literate is still far-off. This study interviewed 12 elementary school principals from Alabama, California, Washington, and two Canadian provinces - Alberta and Ontario. Employing the research method of grounded theory, this study gathered information on principals' knowledge/skills regarding data, the roles that data played at their respective schools, and the processes used when working with data. Findings revealed additional themes to current empirical literature from the past 10 years. Furthermore, the pressures of accountability measures in the form of benchmarks played a significant role when it came to planning school improvement initiatives. Merging evidence from interviews and empirical literature an incipient framework was created illustrating the factors that make up elementary principals data literacy.
\end{abstract}

Keywords:Data Literacy, Data Use, Decision Making, Principals, Leadership

The accountability movement has established scores of data for educational use. The abundance of data has afforded educators the opportunity to fundamentally change the way they meet the needs of their diverse students. If they choose to make it a priority, then data used for decision making in areas connected to leadership, policy, and curriculum and instruction, can be strategically focused on improving student achievement. Principals having access to data can use it as tool to aid their strategic planning at the school; but, first, they must attain a level of proficiency/expertise in the matters of using data for praxis. When principals are given time, context, and skills to use data, student achievement improves (Schildkamp \& Kuiper, 2009). Various schools and districts have established new initiatives encompassing data use with intentions of rectifying problems that are specific to their locale. This drive to enhance educator capacity has come with mixed results. Those that have achieved moderate or major improvement in student achievement continue to be a rarity. Though there is the general understanding suggesting that a general link between principal understanding and knowledge of data when present supports organizational and instructional leadership, professional development, and student-centered learning has yet to be fully realized. Therefore, this study set its focus in an effort to gain a better understanding of data literacy by examining elementary principals' skills, perceptions, and applications of data. The following research questions were used:

(1) What knowledge/skills are behind the use of data by elementary school principals?

(2) How do elementary principals view the role of data in leading school improvement?

(3) How do elementary principals describe their use of data in leading school improvement?

Early research on data literacy originated from business circles painting it as a broad and complex phenomenon. In education, despite the testing and accountability movement which has amassed huge sums of student data; educators have little or no knowledge of the concept. 
A solution to this matter cannot simply rely on the adage of just borrowing from the business community, as previously realized in many previous attempts, directly applying solutions from other fields have tended to fail. Educators will need studies on data literacy that specifically concentrate on education.

With principals playing a vital role in student learning, second only to the classroom teacher (Leithwood, Louis, Anderson, \& Wahlstrom, 2004), principal data literacy skills can be argued as a good starting point. They are in the position of leadership at their respective schools, thus giving them the opportunity to guide and set educational direction by means of sharing through instruction, demonstration and coaching. As well, it is typically the principal that is given the task of first sorting through the stacks of data and charged with making sense of it all.

\section{Context and Contemporary Issues}

The No Child Left Behind Act (NCLB) restarted the Elementary and Secondary Education Act of 1965 and intensified a focus on accountability (Jacobs, Gregory, Hoppey, \& Yendol-Hoppey, 2012). What followed was a movement towards high-stakes testing requiring student achievement to meet specific benchmarks for a given year and an ultimate goal of having every single child in the United States (U.S.) attaining proficiency by 2014 (Hargreaves \& Fullan, 2012). Consequently, such demands fundamentally changed how school leaders were to proceed with school leadership (Elmore, 2005).

Policymakers were compelled to use student achievement data as the central focus for instructional decisions and educators were to be held accountable for student performance (Duke\& Landahl, 2011; Ingram, Louis, \& Schroeder, 2004; Jacobs et al., 2012; Lauen, \& Gaddis, 2012). Though it may have been expected that such policy directives would have caused educators to use data; research has shown otherwise (Monpas-Huber, 2010). Yet, studies continue to come forth with a wide range of ideas to working with data. As of late, insights into the factors that facilitate principals' data use are becoming more prevalent in empirical literature. Such research has yielded evidence on how principals can lead instructional change by means of collaborating with teachers. Leithwood, Louis, Anderson, \& Wahlstrom (2004) concluded that classroom instruction was the greatest school level impact on student achievement followed by school leadership having the second greatest effect. This supposition helped verify earlier findings demonstrating principals' effectiveness in impacting student learning and achievement through their role as instructional leaders (Hallinger \& Heck, 1998; Leithwood et al., 2004; Valentine \& Prater, 2011).

With principals playing such a vital role in student learning the importance of making good decisions is imperative. This is where data can perform an integral part in the process. Principals attempting to provide effective strategies when using data, typically, become muddled on how to do so. Past studies mention how school administrators' have a lack of willingness to analyze school data and interconnect data with curriculum and instruction (Means et al., 2009; Schildkamp \& Kuiper, 2009; Author). This is partly due to having a lack of knowledge and the time to sort through massive amounts of data (Sanzo, Sherman, \& Clayton, 2011). Shen \& Cooley (2008) discovered that principals were confused, especially when data was in a format that was raw or unprocessed -- "Only when student achievement data was analyzed in conjunction with other school and district data (e.g. program changes and teaching strategies) that resource allocation could be adjusted and learning enhanced" (p. 321). Sanzo, Sherman, \& Clayton (2011) also found that if student data were managed properly by principals, data could become a means to connect achievement with curriculum, instruction, and teacher professional development.

Existing research describing data literacy skills and knowledge reveals the complexity of using data, as well, there is little agreement about data literacy as a construct (Mandinach \& Gummer, 2012a; Mandinach \& Gummer, 2013). Furthermore, educators primarily perceive data literacy as the ability to decipher summative assessments to build instructional plans in the hopes of achieving satisfactory student achievement. Information specialists need to be toolmakers (Drucker, 1992). Accordingly, principals need to be skilled in interpreting and evaluating data so to develop strategic plans for the many challenges that exist in their respective schools. However, only a few administrators embody a degree of data literary skills that can be considered proficient (Shen \& Cooley, 2008). In the present environment of accountability most principals have tried to make use of data with aspirations of attaining productive outputs; yet, became perplexed on how to do so and to make sense of the entire process. One can assume when educators do begin to understand student data the possibilities of undertaking issues of the whole-school is possible; but this will require in depth expertise (Chick \& Pierce, 2013). Earl, Fullan, \& Katz (2006) outlined an inventory of what makes an educator leader data-literate: 
(1) thinks about purpose(s) -- data-literate leaders realize that they need different data for different purposes; (2) recognizes sound and unsound data; (3) knowledgeable about statistical and measurement concepts; (4) makes interpretation paramount -- interpretation requires time, thoughtfulness, reservation of judgments and open challenge of, as well as support for, ideas; and (5) attention to reporting and to audiences. (p. 6)

In addition, Coburn \& Turner (2011) described the processes of data use and the role of interpretation, as a means for individuals or groups to begin noticing certain patterns in the data.So, what is data literacy? In the educational context, Bruce (2000) described data literacy as "information literacy", the understanding of the complexities of interacting with information. Stambler (2013) referred to it as "the ability to consume for knowledge, produce coherently and think critically about data" (p. 2) and to have the "ability to ask and answer meaningful questions by collecting, analyzing and making sense of data encountered in our everyday lives" (p. 3). Lastly, Mandinach \& Gummer (2013) offer one of the more thorough definitions,Skills include knowing how to identify, collect, organize, analyze, summarize, and prioritize data. They also include how to develop hypotheses, identify problems, interpret the data, and determine, plan, implement, and monitor courses of action. The decisions that educators need to use data to inform are multiple and diverse, and data literacy is tailored to the specific use ( $\mathrm{p}$. $30)$.

With evidence suggesting that data literacy can assist school leadership which, in turn, supports instruction resulting in improved student achievement warrants further investigation.

\section{Methods}

\section{Sources of Evidence}

Scout, ProQuest Dissertation and Theses, EBSCO Discovery Service, and Google were used in search of literature pertaining to data literacy. Going back as far as 30 years, papers were collected and evaluated. Earlier studies were found to be more concentrated on big data, which is, different from data literacy. Big data involves large scale storage and processing; whereas, data literacy is the ability to derive significant information and apply data. The process of assessing the worthiness of an article/dissertation involved a systematic appraisal of its originality, research design, results, implications for research, and theory into practice.

\section{Sample}

The sample for this study included 12 elementary principals from public schools in Canada and the United States. A purposeful sampling approach was applied for the selection of principals. The number of principals and the province or state were as follows: Alabama -5 ; Alberta -3 , California -1 ; Ontario -1 ; and Washington -2 . These principals were selected by superintendents, professors, and colleagues in regard to their abilities to make use of data for planning and general school operations.

\section{Grounded Theory}

This study made use of the procedures in Grounded Theory Design to generate the incipient framework. Introduced by Glaser and Strauss (1967), Grounded Theory generates theory from information collected from documents, interviews, and observations. In essence, the theory is derived from the data, or "grounded in the data" (Creswell, 2012, p. 423). Theories born out of this design are seen as explaining a process and, as well, considered to be still evolving (Merriam, 2009).

Saturation of a study's categories is the fundamental goal when employing grounded theory design. When the gathering of additional information no longer can generate new insights or alter themes then saturation has been realized (Charmaz, 2006; Creswell, 2014). The researcher seeks for specific interpretations and, as a result, the emphasis is not on sample size but more on sampling adequacy (Charmaz, 2014).

Grounded Theory constantly compares findings taking an initial occurrence and assessing it with other occurrences in the same sample (Charmaz, 2014). The comparing of findings will continue as long as there are comparisons to be made. As this is being done, the researcher makes comparisons within levels of conceptualization until a theory emerges (Merriam, 2009).

\section{Data Collection}

For this study the initial sample was comprised of four principals followed with a second round of interviews that had four more principals answering to a revised list of questions. 
The questions were revised stemming from the data provided by the first group. This similar process was done, yet again, between the second and third groups of principals. Theoretical sampling provided constant direction during research (Glaser \& Strauss, 1967). Each interview lasted 30-45 minutes with just the interviewer and interviewee being present. Interviews were either in-person at principals' offices or by phone or Skype for those located long distance - out of state or country. Questions were open-ended allowing principals the freedom to elaborate on matters that they deemed as significant.

Following each interview, the researcher reserved time to do some memo-writing that typically consisted of a page or two reflecting on the conversation. If any particular themes, categories, or issues stood out, these were noted as potential codes. The memos were a means to allow for deeper reflection focusing on particular findings.

\section{Data Analyses}

This was followed with the transcribing of the dialogue and, finally, three rounds of coding were performed on the data. This process was standard practice after all interviews. A zigzag data collection process and the constant comparative approach were used (Creswell, 2012). Grounded theory employs an emerging design framework whereby research when collected is coded to determine actions. Coding for actions provided the researcher with directions to where to explore, make comparisons between data, and the opportunity to postulate about possible emergent links (Charmaz, 2014). That is why three hierarchical levels of interviews were scheduled. The first level, consisted of 4 principals, these interviews assisted in altering the questions for the second group of 4 principals. This process was repeated yet again for the third and final group of 4 principals.

Coding consisted of three phases: an initial; a second coding session that was much more focused analytically; and a third, theoretical phase, searched for an emerging framework from the collected data. In all, focused coding meant using the most significant and substantial used codes stemming from the interview material and sorting through and analyzing larger amounts of data. Decisions about which initial codes made best analytical sense to categorize data was used to develop the next round of questions in the hopes of "digging deeper" and threshing out a possible framework (Charmaz, 2014).

The researcher took account of documents mentioned by principals during interviews. Either during or after the interviews, the researcher inquired to view the texts or any material related to data use. Website addresses were noted for on-line information.

\section{Results}

All but 2 schools had an assistant-principal. The number of teachers and staff varied from 25 at the smallest to 61 at the largest populated school. Seven schools were located in urban settings, 4 rural, and 1 in a suburban environment. Eight principals considered their student populations as high poverty. Ten schools had met or exceeded state benchmarks, the other 2 schools not meeting state benchmarks were improving on state tests for the past two years. Lastly, 9 out of the 12 schools had seen student population growth for the past three years ranging $5-8 \%$ annually.

Initial coding analysis of interview transcripts and memos identified a total of 45 variables. The second round of coding recognized 16 themes -- 5 linked to principals' knowledge/skills, 3 on the role that data plays to leading school improvement, and 8 on how principals described data. 
Table 1

Variables

BenchmarksInterpretation

Standards

Programs

Feedback

Motivation

Outcomes

Measures

Analyses

Assessment

Experience

Leadership

Observation

Training

Demographics

Informal Information
Time

Commitment

Planning

Improvement

Testing

Test Scores

Student Achievement

Collaboration

Change

Conversations

Practice

Input

Perspective

School Community
Biases

Specialists

Proficiency

Trends

Behavior

Tool

Protocol

Culture

Identification

Relevancy

Decision-Making

Process

Respect

Investment

Syntheses

Table 2

Themes

Knowledge/Skill

Collect

Analyze

Synthesize

Training

Experience

Role
Classroom Instruction
Teacher Efficiency
Parental Support

Description

Student Attendance

Discipline Referrals

Demographics

Summative Assessments

Formative Assessments

Teacher Attendance

Teacher Satisfaction

Parent Satisfaction

\section{Knowledge/Skills - Collect, Analyze, Synthesize, Training, and Experience}

What knowledge/skills are behind the use of data by elementary school principals? The results indicated that, on the whole, principals viewed data as predominately being student scores on summative assessments. This is comparable to what Mandinach \& Gummer (2013) concluded that educators tended to associate data as assessment results.

This study found that principals were more inclined to merely using summative assessment materials and to use only district mandated data meetings to review data. These meetings were anywhere from two weeks to a month apart. In most instances, the principal or assistant-principal would attend along with a data coach (if available) and assessment data would be shared with a group of teachers followed with planning to deal with areas of concern. Principals predominately focused on implementing more instructional time on units/topics which students performed poorly. In some schools, teachers were given opportunities to participate in collaborative professional development meetings to create new instructional strategies in an attempt to address student weaknesses. Unfortunately, this was usually as far principals went in taking up the issue of improving student learning.

Shen \& Cooley's (2008) study also indicated that educators who found data too complex often resorted to foregoing or doing the minimum. This study heard no principal overlooking data; but it was all too familiar to have principals describe how they followed district-imposed guidelines when dealing with student data and shied away from self-designed solutions for their own respective schools. The schools in the study shared many similarities; yet, each school was unique. It was found that the majority of principals struggled to address matters distinctive to their schools. This may be so due to the use of generic strategies supplied by district offices by means of directives. Each school has qualities and traits that are only held by its persons (Spillane, 2012). For that reason, school data must be handled as distinctive and the planning of strategies must also be understood as such. 
All principals touched on using other forms of data such as: attendance, discipline referrals, teacher attendance, and teacher evaluations. The few principals who expended more data tended not to wait for data meetings to implement new initiatives. They responded to problems, more often than not, quicker than those resolved to just data meetings. These same principals also held a reasonable zone of comfort with data launching and administering their own programs at their schools.

When it came to the use of state or provincial summative tests the patterns of data use by the Alberta principals reflected similarly to those from Alabama and Washington. The process generally consisted of a broad overview of the scores for each grade, class, and the specific topics making up the test. This was followed with a closer look at student subgroups and then a going over of each student. For example, Principal \#5, in October, would go online to retrieve the previous year's Provincial Achievement Test (PAT) scores. After downloading the spreadsheets, he would organize the material into grades -- grades 3 and 6 . Then he continued by grouping the material into classes - digital folders were created and titled by classroom teacher. Summative scores were highlighted and noted to determine student achievement for each grade and classroom. He viewed this process as an opportunity to see first-hand the level of success per grade and which classroom teachers had students scoring proficiently or not. "I could quickly see which teachers needed help or weren't doing well in the classroom." Furthermore, by organizing the PAT scores into subgroups, for instance, grade 3multiplication scores on the math achievement test, this enabled him to decide if the grade 3 teachers were succeeding in teaching their students the skill.

\section{Description of Data -- Student and Teacher Attendance, Student Discipline, Demographics, Summative and Formative Assessments, and Teacher and Parental Satisfaction}

Principals identified data as: (1) student attendance; (2) teacher attendance; (3) student discipline referrals; (4) demographics; (5) summative test scores; (6) formative assessments; (7) teacher satisfaction; and (8) parent satisfaction. However, the level of uniformity between principals' descriptions of data varied considerably. This explained why there was a degree of distinctiveness for each principal's approach to data.

Principals that demonstrated an ability to exercise many different strategies when using data also showed a higher level of data capacity. They utilized several well-planned policies/courses of action to address the needs of the school. These principals were also more inclined to initiate goals for school improvement. Principal \#3 as identified in this study realized that the survey information collected annually by the school district lacked information on teacher satisfaction. Having the self-confidence that he had the ability to craft a survey he went ahead and constructed one. With the superintendent's permission he used the survey to collect valuable information that previously was unknown and unattainable.

Besides using data for the purpose of improving instruction, employing data use to enhance teacher efficiency was the second most important function for principals. Beginning with teacher attendance, a group of principals monitored this area with considerable interest. These principals considered consistent regular teacher classroom instruction vital for student learning success. Teachers with issues of chronic absenteeism were usually summoned to meet with the principal in an effort to end the problem. We looked at teacher attendance: How many days did they miss? Did they miss these days for professional development reasons? How many sick days are they taking? How many personal days did they take? We had discussions with these teachers. (Principal \#2)

Principal \#7 went as far to proclaim that over his tenure at his present school, he had noticed classrooms with teachers chronically absent had more discipline problems and student academic performance tended to be below the norm at the school. He noted that he could not pinpoint that teacher absenteeism was the sole factor to these outcomes but was convinced it did play a part.Take for example of a grade 4 class we had here at the school about 3 to 4 years ago. She (teacher) was notoriously late and liked her Fridays and Mondays. What I mean here she would extend her weekends to long weekends. We had three grade 4 classes and her class ended at the bottom even though the kids were no different to the make-up of the other classrooms.

The principals' data proficiency/expertise comes into play when it pushes him/her to forego biases, assumptions, and experiences (Coburn \& Turner, 2011) andinterpret data with thoughtfulness, careful judgment and be open to an array of possibilities (Earl, Fullan, \& Katz, 2006). This study noticed that principals demonstrating a level of proficiency with data - the use of a variety of data sources - were more adept to designing strategies to address school needs. 


\section{The Role of Data - Classroom Instruction, Teacher Efficiency, and Parental Support}

Principals expressed that the most important role of data was to guide and improve classroom instruction. This was primarily done by reviewing results of students' progress on summative and formative assessments. Principals believed if student data was managed properly, data could become a means to directly connect curriculum and instruction improvement, teacher professional development, and the allocation of human and fiscal resources to improve student academic achievement. Principals had the general sense that data was a resource to be used for planning, be it, in the classroom or some other facet in the operating of the school. Data for instructional planning was by far the most shared concept among principals.

Data from ACT Aspire scores, classroom tests, quizzes, and assignments, and from programs the likes of DIBELS and GlobalScholar provide information that can be used to improve instruction. As educators, we are responsible of analyzing these materials and constructing a plan for instruction that's better than the previous one. (Principal \#11)

I would define it as a tool to help us to see if our instruction meets the needs of our students. It's a tool. We always talk about it as a tool for instruction it helps you move in the direction where you have to go. (Principal \#2)

Noting back to Principal \#11, her notion that data primarily stems from test assessments was similar to half of the principals.

Three administrators referred to school improvement when defining data. Any measure that can be used to improve situations is data. I think you can look at data to not only look for problems but to look for strengths. Data use in education it seems is fixed on finding weaknesses and then finding ways to improve. Data is about achievement. As an administrator, we are expected to make things better and we should strive to improve things for students. (Principal \#10)

PLCs were the main course of actions for principals when it came to proceeding with changes to curriculum and instruction. In the PLCs, principals with their teachers looked over assessment scores and determined what areas needed improvement. Plans were constructed to address shortcomings along with instructional approaches. Most principals had access to data coaches, situated either at their school or from the district central office. All the principals revealed that the use of assessment data played an imperative role when it came to planning instruction. Principal \#3, for instance, mentioned, "We look at students' progress at different times of the year and forward the results to our PLCs to guide instructional planning". The use of PLCs to integrate student assessment results for planning purposes was a common theme. Some of the principals used the time in PLCs to work directly with teachers or team leaders looking over assessment materials and then determining what areas needed improvement. In some circumstances, reports were written and forwarded to individual teachers for instructional implementation. For principals who had access to data coaches there was some support; but, with many of these coaches situated at central offices with heavy caseloads thanks to being responsible to a group of administrators, timely responses were rare.

Principals revealed that the capacity to collect, analyze, and synthesize data were all necessary to fully maximize the value of data. What principals needed most were opportunities to learn more about data use. In graduate school I received some training. When I began my career in administration, I received a little bit more, but nowhere near enough to be ready when I became a principal. Over the years it has gotten better and we are receiving a lot more training on data, however, I have so much more to learn. Honestly, I'm not sure if I'll ever get there. (Principal \#10)

In regards to the role of data, principals for the most part squarely concentrated on instructional planning and improvement. In some ways this can be considered a positive result considering principal instructional leadership is the second most important feature to student achievement (Leithwood et al., 2004). Yet, the elementary principals in this study found it particularly challenging when pressed to explain why they were using data, other than for instructional purposes.

Principals exhibiting the ability to use a variety of data when making decisions were more inclined to expand the role of data. Such as the principal that became aware of a classroom that was underachieving on summative test scores, he began examining the matter by not only centering on the teacher's instructional abilities but looked into other factors as well. It became apparent that there was an absenteeism problem with the students and the teacher. The act of exploring all accessible data enabled the principal to better address the issue. 
In other words, exhibiting more knowledge/skill when working with data enabled him to diagnose the situation more deeply and conclude with a clearer picture of the problem. Thus, principals who exhibited a wider array of analyses skills when working with data were more likely to avoid an intuitive response to situations.

When a principal was willing and able to utilize data, he/she tended to involve more applications. The role of data involved the securing of essential data to enact programs. For example, a principal recognized that many of the indigenous males in his school were missing from school for weeks at a time in the months of November and April. The lengthy periods of absence obviously impacted their learning. So, he made calls and invited the parents to come meet him at the school and, in some cases, he made home visits in an attempt to uncover why this was happening. It became clear to him that the reason for this chronic absenteeism, at this particular time of year, was because of the cultural practice of having teenage boys from ages 12 and up to take part in the annual hunt or fishing expeditions. The principal now understood why they were absent, but more importantly, a solution to this issue would require an approach far different from the norm.

\section{Incipient Framework}

Data reports results, delivers ideas, and can be used for designing new and improved structures (Pierce, Chick, Watson, Les, \& Dalton, 2014). Schools are no different than other organizations inundated with challenges. In fact, principals in this study claim that the challenges schools face today continue to grow. State and school district policymakers are increasingly asking educators to use data to inform practice. Though there is this emphasis, the building of human capacity around data use is lacking (Mandinach \& Gummer, 2013).This study focused on questioning elementary principals in three areas related to data literacy: (1) What knowledge/skills are behind the use of data by elementary school principals? (2) How do elementary principals view the role of data in leading school improvement? And, (3) How do elementary principals describe their use of data in leading school improvement? Merging the information gathered from interviews with past empirical literature an incipient framework has been constructed to further our understanding of data literacy in the educational context. Principals exhibiting the ability to use a variety of data during decision-making were more inclined to expand the role of data. The act of examining all accessible data enables the principal to better address issues. Likewise, exhibiting more knowledge/skill when working with data enables a more multifaceted approach to problems. Principals exhibiting such expertise demonstrated a wider array of skills during analyses and syntheses and, at the same time, avoided simple intuitions. Problems were handled with a wider lens, scoping for answers beyond the norm.

A few of the principals that demonstrated a reasonable confidence when using data applied various descriptors and employed roles that were best suited for the particular situation. They were able to anticipate the needs of students, teachers, and the school community. In other words, these principals noticed certain patterns in the data, the ability to interpret data evoking responses that were on point and purposeful.

Assembling together the evidence gathered from interviews indicated that the 12 elementary principals considered data literacy as being made up of their understanding and application of data knowledge/skills, role of data, and description of data. Each of the three constructs are defined by a list of factors deemed as respective functions.

If elementary principals were to attain levels of data literacy entailing abilities to: identify areas in need of improvement, construct strategic plans, carry out implementation, and evaluate results, student achievement would certainly benefit. Correspondingly, teachers would likely take positive strides in the areas of curriculum development and classroom instruction and, most likely, become self-motivated to increase their own data literacy. 


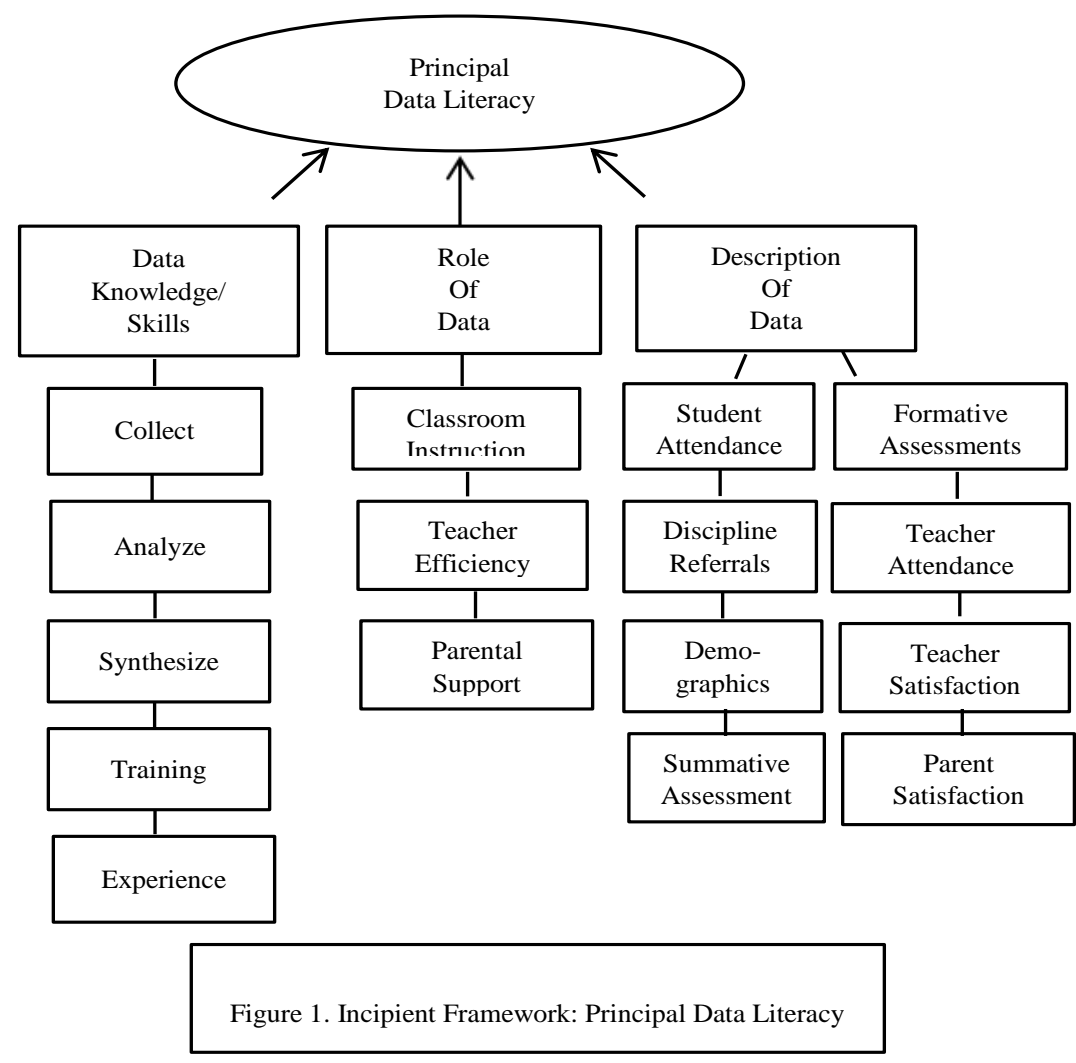

\section{Discussion and Conclusion}

The findings of this study suggest that: (1) the quantity of literature on the topic of principal data literacy is thin and in the early stages of development, therefore, the incipient framework presented acts as a starting point to developing a theoretical framework on the subject; (2) the themes identified principals' knowledge/skills, the roles, and how data are applied to improve student learning; and (3) an understanding of the concepts that make up data literacy are interconnected.

\section{Implications}

\section{For Principals}

For most principals the pressures to have students meet or exceed benchmarks were front-and-center. Accountability measures imposed by state/provincial departments of education have to a large degree created an environment heavily focused on summative assessment scores. This was evident from principals' responses when asked about the types of data used, for what role, and why?

Data meetings and PLCs mainly concentrated on results garnered from ACT Aspire, Provincial Achievement Tests, and other numerous state tests. This shaped classroom instruction that was primarily geared towards meeting state/provincial and school district benchmarks. The idea of increasing student learning is well-intended; however, other mediums are largely ignored by principals. Those principals applying data, such as, student attendance, teacher attendance, demographics, student behavioral referrals, and formative assessments were more inclined to lead additional initiatives to improve student learning.All told, principals with a greater vision on data operated with a greater sense of confidence in initiating changes in their respective schools. These same principals talked about the ability to identify relevant information and showcased capabilities of pinpointing areas of concern, putting a plan in place, and maximizing time and effort.

\section{For Policy-Makers}

Educational policy makers have a vital role to play when it comes to data and its use in schools. From politicians to state department officials, trustee boards, and central office staff have indicated their intentions for accountability in k-12 education. 
They have created an environment of standardization that has produced vast sums of data. Yet, educators are in the dark on what to do with it all. The principals interviewed indicated to receiving some hands-on training on data use through district workshops; but, a desire for more was evident. Principals mentioned the need for higher quality data. To make better informed decisions, principals require data that embodies the challenges and provides different options to resolving them. In addition, principals would greatly benefit to better access to data coaches and self-help software. Data coaches, in particular, could help in the areas of planning teacher team meetings, facilitating Data-Driven Decision-Making, and guiding principals and faculty by means of collaborative inquiry.

Graduate schools offering principal preparation programs ought to take a leading role when it comes to data training. With the expectations of principals comprehending data analyses; higher education can play a vital part in preparing school administrators for this responsibility.

\section{Limitations of the Study}

The study was limited to elementary principals, thus, omitting input from middle school and high school principals. As well, central office staff and assistant principals were excluded.

The collection of data for the study was attained through interviews conducted in-person, by phone, or on Skype. The interviewees responded to open-ended questions. No cross-examinations or follow-up interviews were performed; therefore, information gathered could not be verified as entirely accurate (i.e., did principals actually perform the work they purported).

Although social, political, and economic factors, such as socioeconomic status (SES) of students were known and considered they did not play a central role in determining the sample. As a result, the effects of SES on principal data literacy cannot be distinguished. Professors, superintendents, deputy-superintendents, and principals were asked to nominate elementary principals deemed proficient or successful administrators in the use of school data that improved student learning. Though there were guidelines to assist nominators, subjectivity still played a role in their decisions.

\section{Recommendations for Future Research}

The empirical literature leading up to this study expressed the shared belief that data enabled principals to perform better in such areas as instructional leadership, parent and community relations, budgeting, and so forth. Principals skilled in the use of data had the ability to decide what it could be used for and how to apply it. However, at the same time, researchers indicated that principals, in large part, struggled with data. This study explored what elementary principals perceived as data, the processes used to derive understanding from data, and how they applied data to practice. In the end, new themes/categories were uncovered which can now aid researchers to better understand the data literacy of school leaders.

Additional research should be carried out with middle and high school principals to compare and add to the findings of this particular study. Future studies may wish to explore data literacy of teachers as well. All principals involved in this study indicated the significance of teacher participation, especially, in the development of classroom instruction. Situated at the frontline, teachers were considered imperative in the process of implementing student data for increased student learning.

\section{References}

Bruce, C. (2000). Information literacy research: dimensions of the emerging collective consciousness. Australian Academic \& Research Libraries [serial online]. 31(2), 91-109.

Charmaz, K. (2006). Constructing grounded theory: a practical guide through qualitative analysis. London: SAGE.

Charmaz, K. (2014). Constructing grounded theory ( $2^{\text {nd }}$ ed). Thousand Oaks, CA: Sage Publications Inc.

Chick, H. \& Pierce, R. (2013). The statistical literacy needed to interpret school assessment data. Mathematics Teacher Education and Development, 15(2), 195-217.

Coburn, C., \& Turner, E. (2011). Research on data use: A framework and analysis.Measurement,9 (4), 173-206.

Creswell, J.W. (2012). Planning, conducting, and evaluating quantitative and qualitative research. Boston, MA: Pearson Education, Inc.

Creswell, J.W. (2014). Research design: qualitative, quantitative, and mixed methods approaches. Thousand Oaks, CA: SAGE Publications. 
Drucker, P. (1992). Be data literate --know what to know. The Wall Street Journal, 16.

Duke, D. L., \& Landahl, M. (2011). 'Raising tests scores was the easy part': A case study of the third year of school turnaround. International Studies in Educational Administration (Commonwealth Council For Educational Administration \& Management (CCEAM), 39(3), 91-114.

Earl, L. M., Fullan, M., \& Katz, S. (2006). Leading schools in a data-rich world: Harnessing data for school improvement. Thousand Oaks, California: Corwin.

Elmore, R. (2005) Accountable leadership. The Educational Forum, 69(2), 134-142.

Glaser, B. G., \& Strauss, A. L. (1967). The discovery of grounded theory; strategies for qualitative research. Chicago, Aldine Pub. Co.

Hallinger, P. \& Heck, R.H. (1998). Exploring the principal's contribution to school effectiveness: 1980-1995. School Effectiveness and School Improvement, 9, 157-191.

Hargreaves, A. \& Fullan, M. (2012). Professional capital: Transforming teaching in every school. New York, NY: Teachers College Press.

Ingram, D., Louis, K. S., \& Schroeder, R. G. (2004). Accountability policies and teacher decision making: Barriers to the use of data to improve practice. Teachers College Record, 106(6), 1258-1287.

Jacobs, J., Gregory, A., Hoppey, D., \& Yendol-Hoppey, D. (2012). Data literacy: Understanding teachers' data use in a context of accountability and response to intervention. Action in Teacher Education, 31(3), 41-55.

Lauen, D., \& Gaddis, S. (2012). Shining a light or fumbling in the dark? The effects of NCLB's subgroup-specific accountability on student achievement. Educational Evaluation and Policy Analysis, 34(2), 185-208.

Leithwood, K., Louis, K., Anderson, S. \& Wahlstrom, K. (2004). How leadership influences student learning. New York, NY: Wallace Foundation

Mandinach, E. B., \& Gummer, E. S. (2012a). Navigating the landscape of data literacy: It is complex. Washington, DC/Portland, OR: WestEd/Education Northwest.

Mandinach, E. B., \& Gummer, E. S. (2013). A systemic view of implementing data literacy in educator preparation. Educational Researcher, 42(1), 30-37.

Merriam, S. B. (2009). Qualitative research: A guide to design and implementation San Francisco, CA: JosseyBass.

Monpas-Huber, J. B. (2010). Explaining teachers' instructional use of state assessment data: A multilevel study of high school teachers in Washington state. Journal of School Leadership, 20(2), 208-237.

Pierce, R., Chick, H., Watson, J., Les, M., \& Dalton, M. (2014). A statistical literacy hierarchy for interpreting educational system data. Australian Journal of Education, 58(2), 195-217.

Sanzo, K. L., Sherman, W. H., \& Clayton, J. (2010). Leadership practices of successful middle school principals. Journal of Educational Administration, 49(1), 31-45.

Schildkamp, K., \& Kuiper, W. (2009). Data-informed curriculum reform: Which data, what purposes, and promoting and hindering factors. Teaching and Teacher Education, 26, 482-496.

Shen, J., \& Cooley, V. E. (2008). Critical issues in using data for decision-making.International Journal of Leadership in Education, 11(3), 319-329.

Spillane, J. P. (2012). Distributed Leadership. San Francisco, CA: Jossey-Bass.

Stambler, L.G. (2013). Data literacy: Literacies for the digital age to teach in the K-12 classroom. Developed for the Pier Institute: Global Youth in the Digital Age. Yale University. Retrieved from http//www.yale.edu/macmillian/pier/classroom-resources/11.\%20DATA\%20LITERERACY.pdf

Sun, J.- P., Przybylski, R., \& Johnson, B. (2016). A review of research on teachers' use of student data: from the perspective of school leadership. Educational Assessment, Evaluation and Accountability, 28(1), 5-33.

Valentine, J. W. \& Prater, M. (2011). Instructional, transformational, and managerial leadership and student achievement: High school principals make a difference. NASSP Bulletin,95 (5), 5-30. 